\title{
A catalytic-independent function of human DNA polymerase Kappa controls the pool of the Checkpoint Kinase 1
}

Marina Dall'Osto ${ }^{1 *}$, Laura Pierini ${ }^{2} *$, Nicolas Valery ${ }^{1}$, Jean-Sébastien Hoffmann ${ }^{3 * *} \&$ Mariejeanne Pillaire ${ }^{1 * *}$

${ }^{1}$ Cancer Research Center of Toulouse, INSERM U1037, CNRS ERL5294, Université Paul Sabatier Toulouse III, Equipe labellisée Ligue Contre le Cancer, Laboratoire d'excellence Toulouse Cancer, 2 Avenue Hubert Curien, 31037 Toulouse, France

${ }^{2}$ AP-HP, DRCI Hôpital Saint-Louis, 1 avenue Claude Vellefaux, 75010 Paris

${ }^{3}$ Laboratoire d'Excellence Toulouse Cancer (TOUCAN), Laboratoire de pathologie, Institut Universitaire du Cancer-Toulouse, Oncopole, 1 avenue Irène-Joliot-Curie, 31059 Toulouse CEDEX, France

*These authors contributed equally to the study

** To whom correspondence should be addressed.

Dr. Marie-jeanne Pillaire, INSERM Researcher (marie-jeanne.pillaire@inserm.fr)

Dr. Jean-Sébastien Hoffmann, INSERM Research Director (jeansebastien.hoffmann@inserm.fr)

Address: (CRCT), 2 avenue Hubert Curien 31037 Toulouse, FRANCE. Phone: (+33) 582741 656. Fax: (+33) 562744558

Running title: DNA polymerase Kappa controls Chk1 stability 


\begin{abstract}
DNA polymerase kappa (Pol $\kappa)$ has been well documented thus far for its specialized DNA synthesis activity during translesion replication, progression of replication forks through regions difficult to replicate and replication checkpoint at stalled forks.
\end{abstract}

Here we unveiled an unexpected role for Pol $\kappa$ in controlling the stability and abundance of Chk1, the major mediator of the replication checkpoint. We found that loss of Pol $\kappa$ decreased the Chk1 protein level in the nucleus of four human cell lines. Pol $\kappa$ and not the other Y-family polymerase members is required to maintain the Chk1 protein pool all along the cell cycle. We showed that Pol $\kappa$ depletion affected the protein stability of Chk1 and protected it from proteasome degradation and the replication recovery defects observed in Pol $\kappa$-depleted cells could be overcome by the re-expression of Chk1. Importantly, this new function of Pol $\kappa$ does not require its catalytic activity, revealing that in addition to its known roles in the replication process, Pol $\kappa$ can contribute to the maintenance of genome stability independently of its DNA synthesis activity.

Keywords: DNA polymerase Kappa / Checkpoint kinase 1 /Chk1 stability/ fork restart 


\section{INTRODUCTION}

Cells have to continuously cope with a variety of DNA damages induced by the exposure to exogenous and endogenous genotoxic agents. Cellular responses such as signalling, repairing or bypassing the damage are required to deal with DNA damages and avoid the replication fork blockage during S-phase. Cells need to limit the accumulation of stalled forks, a process described as replication stress, in order to restrain transmission of DNA damages to daughter cells (Zeman \& Cimprich, 2014; Técher et al, 2017). An important part of the cellular response to replication stress is the induction of the ATR/Chk1 replication checkpoint which senses stalled replication forks, allows their stabilization and repair, prevents the firing of late replication origins, and inhibits entry into mitosis until the completion of replication (González Besteiro \& Gottifredi, 2015; Zhang \& Hunter, 2014) .

The ATR-Chk1 signaling axis is now described as a tunable brake required during unperturbed cell proliferation to couple the replication of the genome and the cell cycle progression (Panagopoulos \& Altmeyer, 2020). ATR and Chk1 are essential actors in the genome stability maintenance. Indeed, mutations in $A T R$ are responsible for an autosomal recessive disorder called Seckel syndrome (Lecona \& Fernandez-Capetillo, 2018) and Chk1 heterozygosity leads to defects in cell cycle control, accumulation of DNA damages and predisposes cells to cancer (Lam et al, 2004). Under physiological conditions, the depletion of Chk1 decreases the global rate of replication (Petermann et al, 2006, 2010; Técher et al, 2016). To ensure correct connections between replication and cell cycle progression, the abundance of Chk1 that relies on its stability is critical for cellular stress response and checkpoint maintenance (Panagopoulos \& Altmeyer, 2020). One of the most documented modes of regulation of Chk1 is the ubiquitination mediated by the Cullin-Ring E3-ubiquitin ligases Cul1, Cul4A, HUWE1 which ubiquitinate the C-terminal degron like region of Chk1 and target it for proteasomal degradation (Zhang et al, 2009, 2005; Cassidy et al, 2020). This 
ubiquitination-dependent regulation of Chk1 can be directly antagonized by the ubiquitin hydrolases USP1, USP3, USP7 and Ataxin3 which deubiquitinate Chk1 (Cheng \& Shieh, 2018; Guervilly et al, 2011; Tu et al, 2017; Alonso-de Vega et al, 2014).

The translesion synthesis (TLS) is also an important mechanism to respond to replicative stress. It involves the translesional Y-family DNA polymerases Pol $\eta$, Pol $\kappa$, Pol $\iota$ and Rev1 also called specialized polymerases. They facilitate the bypass of DNA lesions that block the replicative DNA polymerases by insertion of nucleotides opposite DNA lesions. They are devoid from exonuclease activity and show a flexible catalytic site able to adapt to damaged DNA template (Guo et al, 2009). Y-DNA polymerases are also implicated in DNA repair mechanisms such nucleotide excision repair or homologous recombination (McVey et al, 2016; Ogi et al, 2010; Lange et al, 2011). In addition to their TLS or repair functions, these specialized DNA polymerases also play critical roles in the replication of non B-DNA and in the prevention of replication stress induced by oncogenes (Bournique et al, 2018; Tsao \& Eckert, 2018; Pillaire et al, 2014; Tonzi \& Huang, 2019). For instance Pol $\eta$ contributes to the stability of Common Fragile Sites (CFS) which have the potential to adopt non-B DNA structures (Bergoglio et al, 2013). The deoxycytidyl transferase Rev1 is required to replicate DNA sequences prone to form G4 secondary structures or enriched in nucleotide repeats (Barnes et al, 2017; Walsh et al, 2013). Similarly, Pol $\kappa$ is required for the replication of structured DNA sequences and rescues the replicative DNA polymerase Pol $\delta$ when it is stalled at repetitive sequences within CFS (Sarkies et al, 2010). Pol $\kappa$ is also needed to maintain viability upon replication stress induced by oncogene activation (Yang et al, 2017) since it is required to protect and to restart the replication forks following starvation of dNTPs (Tonzi et al, 2018). 
Thus far, all these known Pol $\kappa$ functional roles, i.e. TLS, replication of non-B structured DNA and repetitive sequences, DNA synthesis on unwound DNA at stalled forks were entirely associated to its DNA polymerase catalytic activity. Indeed, mutation of the residues D198 and D199 that belong to the catalytic site of Pol $\kappa$ (Lone et al, 2007) abolished the capacity of the polymerase to extend primers in vitro (Ohashi et al, 2000), sensitized human cells to benzo[a]pyrene diolepoxide, mitomycin $\mathrm{C}$ and bleomycin (Kanemaru et al, 2015), decreased the repair of interstrand crosslinks (Williams et al, 2012) or impeded primer synthesis (Bétous et al, 2013) and fork restart (Tonzi et al, 2018) at stalled forks.

The multiple functions of Pol $\kappa$ imply that its cellular level needs to be tightly regulated to avoid perturbation of genome maintenance. In untreated cells, its aberrant recruitment to replication forks in cells depleted for USP1 or p21CDNKN1 leads to a decrease of the fork speed and its overexpression is associated with an instability of CFS, DNA breaks and tumorigenesis in mice (Bavoux et al, 2005; Mansilla et al, 2016; Pillaire et al, 2007). In addition, dysregulation of Pol $\kappa$ expression can affect its normal subcellular localization and can contribute to drug resistance (Peng et al, 2016; Temprine et al, 2020). Pol $\kappa$ depletion in untreated cells induces hallmarks of replication stress with RPA foci formation and $\gamma-\mathrm{H} 2 \mathrm{AX}$ in $\mathrm{S}$ phase which are indicative of endogenous ssDNA accumulation and DNA breaks respectively and common fragile site expression (Bétous et al, 2013; Mansilla et al, 2016) features also observed in absence of Chk1 (Gagou et al, 2010).

Here we unveiled an unexpected role for Pol $\kappa$ in controlling the stability of Chk1 in mammalian cells. We found that depletion of Pol $\kappa$ and not the other Y-family polymerase members, induces a decrease of Chk1 protein level in the nucleus of four different human cell lines. Strikingly, this regulation is independent of the catalytic activity of Pol $\kappa$ and occurs all along the cell cycle. Pol $\kappa$ depletion does not affect the mRNA expression of Chk1 but favors its degradation through the proteasomal pathway. Finally, we found that the replication 
defects observed in Pol $\kappa$-depleted cells is linked to the low abundance of Chk1. Collectively, this work highlights a catalytic-independent function of Pol $\kappa$ in genome maintenance.

\section{RESULTS}

\section{Chk1 protein level is reduced in mammalian cells depleted for Pol Kappa}

To better understand the implication of the DNA polymerase Kappa (Pol $\kappa$ ) in the maintenance of genome stability, we depleted Pol $\kappa$ from different human cell lines and analyzed the Chk1 signaling pathway. We found a decrease of Chk1 protein level in the nuclear fraction of MRC5-SV Pol $\kappa$ depleted cells (Fig 1A to 1C) whereas the level of other proteins implicated in fork progression and ATR/Chk1 pathway such as claspin, TopBP1, Rad18, Rad17, Rad9A or Pol delta were not reduced (Suppl Fig 1A). As a control we treated cells with hydroxyurea, an inhibitor of ribonucleotide reductase which induces the activation of the ATR/Chk1 and the phosphorylation of Chk1 before its down-regulation that can be observed later on (Leung-Pineda et al, 2009). Analysis of Pol $\kappa$ and Chk1 protein levels in different nuclear extracts of MRC5-SV showed a good correlation $\left(\mathrm{R}^{2}=0.906\right.$, Fig 1B). To confirm this observation, we used immunofluorescence microscopy as a second approach. Chk1 fluorescence intensity was significantly decreased after Chk1 or Pol $\kappa$ depletion in the nuclei of MRC5-SV cells (Fig 1C) and importantly the Chk1 protein level was rescued by ectopic expression of the polymerase (Fig 1C and suppl Fig 1C). Thus we revealed here that Pol $\kappa$ depletion leads reproducibly to a decrease in Chk1 abundance in the nucleus, an observation that was not reported in previous studies using whole cell extracts from Pol $\kappa$ depleted cells (Bétous et al, 2013; Mansilla et al, 2016; Tonzi et al, 2018). We verified that indeed there was no correlation between Chk1 and Pol $\kappa$ protein levels in whole cell extracts 
$\left(\mathrm{R}^{2}=0.002\right.$, Suppl Fig 1$)$ as compared to nuclear extracts $\left(\mathrm{R}^{2}=0.906\right.$, Fig $\left.1 \mathrm{~B}\right)$, supporting that the impact on Chk1 level occurs reproducibly in the nuclear compartment. We next checked whether this effect was also observed in additional cell lines. The fluorescence intensity of Chk1 was monitored in more than 500 nucleus of HCT116 and RKO colon cancer cells after depletion of Pol $\kappa$ with or without reintroduction of GFP- Pol $\kappa$ (Fig 1D, 1F and suppl 1D). Transfection with siRNA targeting Chk1 was used as a control of down expression of Chk1 (Fig 1D and 1F). The fluorescence intensity of Chk1 decreased by $37 \%$ and $28 \%$ respectively in HCT116 and RKO transfected with a siRNA targeting the coding sequence of POLK (Fig $1 \mathrm{E}$ and $1 \mathrm{G}$ ) and by $27 \%$ in HCT116 transfected with siRNA targeting the 3'UTR of POLK (Fig 1E). Chk1 protein level was rescued by ectopic expression of Pol $\kappa$ in HCT116 cells (Fig 1D, 1E and suppl Fig 1D). Western blots analysis also confirmed the results in HCT116, RKO and in a human embryonic kidney cell line (293T) (suppl Fig 1E). As in MRC5-SV cells, HU treatment induced a Chk1 protein decrease in the nucleus of $293 \mathrm{~T}$ cells that is amplified by Pol $\kappa$ depletion $(0.5$ versus 0.1 relative quantity of Chk1 in control and Pol $\kappa$ depleted cells respectively) (suppl Fig 1E). Collectively, these data support the notion that Pol $\kappa$ is required to maintain the Chk1 protein level in the nucleus of human cells.

\section{Among the Y-DNA polymerase family, only the Polk depletion causes a Chk1 nuclear drop}

To check whether the effect on Chk1 is specific to Pol $\kappa$, HCT116, RKO and 293T cells were transiently transfected with siRNA targeting the three other Y-family TLS DNA polymerases, Pol eta, iota and REV1, and the Chk1 fluorescence intensity was measured (Fig 2A and 2B, suppl Fig 2C). siRNA transfection efficiencies were concomitantly checked by RT-qPCR (suppl Fig 2A and 2B). While depletion of Chk1 itself, Pol $\kappa$ or USP7, an ubiquitin hydrolase already shown to stabilize Chk1 (Alonso-de Vega et al., 2014) triggered a Chk1 drop in the 
nucleus, the depletion of Pol iota, eta or Rev1 did not, supporting that Chk1 is specifically regulated by Pol $\kappa$.

\section{The Pol $\kappa$ dependent Chk1 downregulation is not due to cell cycle arrest in G1}

Chk1 protein level in human cells has been shown to accumulate in S and G2 phases and display its lowest level in G1 (Kaneko et al, 1999). We confirmed these data as shown in suppl Fig 3A. To exclude the possibility that the Chk1 decrease in Pol $\kappa$ depleted cells is the consequence of an enrichment in G1 population, we compared the cell cycle distribution of

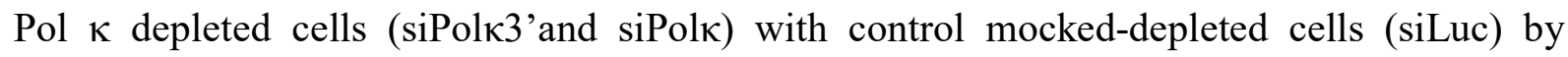
Quantitative Image-Based Cytometry (QIBC, (Toledo et al, 2013)), an experimental approach which monitors the Chk1 fluorescence intensity all along the cell cycle in HCT116 cells and by FACS in RKO cells (suppl Fig 3B). We found that 30 to $38 \%$ of the Pol $\kappa$ depleted cells versus $39 \%$ in controls were in G1 in HCT116 cells (suppl Fig 3B left panel) and $40 \%$ to $45 \%$ of the Pol $\kappa$ depleted cells versus $43 \%$ in controls were in G1 in RKO (suppl Fig 3B right panel), demonstrating that no enrichment in G1 cell population occurred when the pool of Chk1 is affected in Pol $\kappa$-depleted HCT116 and RKO cells with no modification of the global cell cycle progression, in contrast to cells which display a total depletion of Chk1 expression (Fig 3B right panel). When we combined the quantification of Chk1 fluorescent intensity, EdU incorporation and DNA content (DAPI labeling) (Fig 3), we found that Pol $\kappa$ depletion impacted Chk1 protein level in all the phases of the cell cycle. These observations suggest that Pol $\kappa$-dependent regulation of Chk1 does not result from a cell cycle modification.

\section{Pol $\kappa$ controls Chk1 abundance independently of its DNA synthesis activity}

For the Pol $\kappa$ functions such as replication of non-B structured DNA and repetitive sequences, bypass of DNA damages, full activation of the S-phase checkpoint, the catalytic activity of 
the polymerase is required. To determine whether this is also true for maintaining the level of Chk1, cells depleted for Pol $\kappa$ with a 3'UTR POLK siRNA were transfected with a vector coding for the catalytically inactive form of Pol $\kappa$ (GFP-Polk-Dead), and Chk1 level was quantified by immunofluorescence. The results show that, similarly to the WT Pol $\kappa$ (Fig 1C to E), the Chk1 fluorescence intensity was also restored by expression of the Dead Pol $\kappa$ in RKO (Fig 4A) and HCT116 (Fig 4B) cells, demonstrating that the polymerase activity of Pol $\kappa$ is not required to maintain the Chk1 protein level in human cells.

\section{Pol $\kappa$ protects Chk1 from degradation}

Next, we wanted to determine how Pol $\kappa$ affects Chk1 expression. To deal with this question we carried out reverse transcription and real-time quantitative PCR to analyze the mRNA level of Chk1 in Pol $\kappa$ depleted cells with two different siRNA. We did not find any significant difference when compared to control cells in four different cell lines (Fig 5A). This observation rules out any potential implication of Pol $\kappa$ in $C H E K 1$ gene promoter repression, or its binding to the CHEK1 transcript, to explain the down regulation of Chk1. These data are in accordance with the observations presented in Fig $4 \mathrm{~A}$ and $4 \mathrm{~B}$ showing that Pol $\kappa$ reexpression could not restore Chk1 fluorescence induced by a Chk1 siRNA-mediated depletion. It has been reported that Chk1 can be targeted by ubiquitin ligases to control its stability and its degradation through the proteasome (Zhang et al, 2005, 2009; Cassidy et al, 2020). To test if Chk1 instability resulted from proteasomal degradation, we treated Pol $\kappa$ depleted cells with the proteasome inhibitor MG132 to block the proteolysis and we monitored the level of Chk1 by immunoblotting (Fig 5B). The results clearly showed in three different cell lines that the proteasome inhibition lead to a stabilization of Chk1 in Pol $\kappa$ depleted conditions. Treatment of HCT116 with cycloheximide (CHX), an inhibitor of protein synthesis, induced the decrease of Chk1 and p53 protein levels in the control condition and 
only Chk1 was further affected under Pol $\kappa$ depletion (Fig 5C). Addition of MG132 restored Chk1 and p53 levels in CHX treated conditions. Collectively, these data support that the defective Chk1 pool in Pol $\kappa$ depleted cells is not the consequence of a modification of its mRNA abundance but rather the result of its enhanced degradation by the proteasome, and thus Pol $\kappa$ seems to be a requisite factor to stabilize Chk1 protein level in human cells.

\section{The replication defects associated with Pol $\kappa$ loss can be restored by Chk1 ectopic expression}

Considering the fact that Chk1 is required for the global genomic replication in absence of exogenous stress (Petermann et al, 2006; González Besteiro et al, 2019), we asked whether the depletion of Pol $\kappa$ can affect the genome replication to the same extent. We pulse-labeled cells with EdU and we measured the EdU intensity in the S-phase cell population as in figure 3. We found that the depletion of Pol $\kappa$ decreased the EdU incorporation to a similar extent as the Chk1 depletion (Suppl Fig 4), meaning that Pol $\kappa$ is required to maintain the global replication in absence of exogenous stress. Pol $\kappa$ was shown to be required for restart of stalled fork after HU treatment (Tonzi et al, 2018). As Chk1 is also implicated in this process (Hromas et al, 2012; Smits \& Gillespie, 2015), we wondered whether the fork restart deficiency observed by Tonzi et al in RPE Pol $\kappa$ depleted cells can be explained by the attenuated abundance of Chk1 induced by the polymerase depletion. To test this hypothesis, we performed DNA fiber spreading analysis. Cells were labelled with IdU, treated with HU during $1 \mathrm{~h}$ at $1 \mathrm{mM}$, and released in fresh media containing CldU to label the restarting forks (Fig 6). The length of the CldU tracts is indicative of the replication recovery efficiency after fork stalling. As shown in Fig 6, we found that Pol $\kappa$ depletion significantly reduced the track

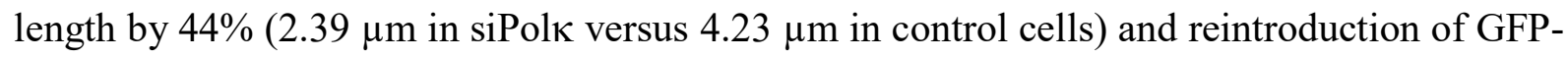

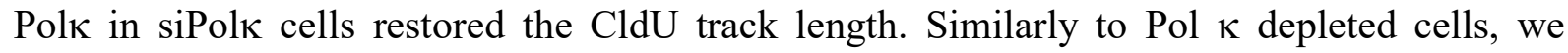


observed that in Chk1 depleted cells the track length is reduced by $46 \%$ ( $2.27 \mu \mathrm{m}$ in siChk1 versus $4.23 \mu \mathrm{m}$ in control cells). Strikingly, we observed that the inefficient fork recovery in Pol $\kappa$-depleted cells was restored by expression of ectopic myc-Chk1, whereas the expression of GFP-Pol $\kappa$ could not restore the fork recovery in Chk1-depleted cells. Importantly these data demonstrate that in addition to the role of Pol $\kappa$ in the fork restart showed by Tonzi et al, the deficiency of the replication stress recovery observed in Pol $\kappa$ depleted cells may rely on an insufficient pool of Chk1 in the nucleus.

Collectively, all these findings highlight a non-catalytic function of Pol $\kappa$ besides its welldocumented TLS function to maintain proper DNA replication and ensure recovery from replication stress through the stability of Chk1.

\section{Discussion}

In the absence of exogenous stress, the depletion of Pol $\kappa$ is associated with increased rates of mutagenesis in mice, DNA breaks, sister-chromatid exchange, expression of common fragile site in human cells and increased number of 53BP1 nuclear bodies in G1 phase cells (Bétous et al, 2013; Hakura et al, 2019; Mansilla et al, 2016; Peng et al, 2016; Tonzi et al, 2018; Stancel et al, 2009). These hallmarks of genetic instabilities can reflect a direct role of Pol $\kappa$ in the genomic replication. Indeed Pol $\kappa$ is required to copy repetitive sequences known to be fork-stalling sites for replicative DNA polymerase delta (Barnes et al, 2017; Walsh et al, 2013), tolerate stress induced by oncogenes (Yang et al, 2017) and promote efficient fork progression under low level of dNTP (Tonzi et al, 2018). We have also previously shown that upon activation of the replication checkpoint with $\mathrm{HU}$, Chk1 phosphorylation is dependent on the presence of Pol $\kappa$ (Bétous et al, 2013) suggesting that Pol $\kappa$ could be involved in the activation of the ATR-Chk1 axis. This has been further confirmed in human glioblastoma cell lines treated by the alkylating drug temozolomide (Peng et al, 2016). All the functions 
reported thus far have been demonstrated to require the catalytic DNA synthesis activity of the polymerase.

Here we present evidences supporting a new catalytic-independent role for Pol $\kappa$ in the cellular homeostasis through the regulation of Chk1 abundance in human cells. We provide evidences that the depletion of Pol $\kappa$ in four independent cell lines induces a decrease of the Chk1 protein level. It is specific to Pol $\kappa$ since this Chk1 reduction is 1) rescued by ectopic GFP-Pol $\kappa$ and 2) not shared by other DNA polymerases, consistent with previous reports where no modification of Chk1 protein level was observed in Pol $\eta$ depleted or mutated cells (Despras et al, 2010). CHK1 knock-out is lethal in mice and Chk1 haploinsufficiency leads to carcinogenesis (Liu et al, 2000). In contrast, the effects of Chk1 instability in Pol $\kappa$ knock-out mice are milder with increased mutagenesis without affecting viability and with no cancer incidence (Stancel et al., 2009), suggesting that low level of Chk1 is enough to maintain genome stability and viability. Interestingly, Gonzalez-Besteiro and colleagues reported recently that indeed in Chk1-depleted cells, low levels of exogenous Chk1 was sufficient to rescue origin firing and restore DNA damage signalling (González Besteiro et al, 2019).

The level of Chk1 in the nucleus depends on a tight equilibrium between synthesis, degradation and nuclear export, and an excess or a lack of Chk1 can be deleterious for the genome stability (Smits \& Gillespie, 2015). Indeed a higher abundance of Chk1 protein level restricts the replication stress induced by oncogenes or therapeutic treatments and contributes to malignant transformation (David et al, 2016; López-Contreras et al, 2012). Conversely, CHK1 deficiency is associated with modifications of replication dynamics, mitotic defects, transmission of under-replicated DNA, and predisposition to cancer (Bétous et al, 2013; Petermann et al, 2006, 2010; Speroni et al, 2012; Técher et al, 2016; Lam et al, 2004). The tumor suppressor p53 has been shown to regulate the mRNA level of Chk1 and to downregulate its expression in response to stress signals (Gottifredi et al, 2001). Our data 
support that Pol $\kappa$ effect on Chk1 is independent of p53 since 1) the mRNA of Chk1 is unchanged in Pol $\kappa$ depleted cells, 2) the reduction of Chk1 is observed in p53 proficient cells (RKO, HCT116) as well as p53 deficient cells (293T and MRC5-SV). We also showed that the Chk1 downregulation cannot be the consequence of a cell cycle effect induced by the depletion of Pol $\kappa$ and Pol $\kappa$ down-regulate Chk1 all along the cell cycle.

Based on our results, we propose that the Chk1 decrease in Pol $\kappa$ depleted cells can be the consequence of a lack of protection against its normal degradation. We observed a faster rate of Chk1 disappearance in Pol $\kappa$ depleted cells that can be antagonized by proteasomal inhibition. We propose that Pol $\kappa$ is a regulator of Chk1 stability as it was already observed for Rad17, another member of the ATR-Chk1 signaling pathway. However how Pol $\kappa$ protects Chk1 from degradation remains to be determined.

Interestingly we showed that the catalytic activity of Pol $\kappa$ is not required to maintain the Chk1 protein level, as the GFP- Pol $\kappa$ dead also restored the Chk1 protein level in cells depleted for endogenous Pol $\kappa$. Non-catalytic function of other polymerases has been previously proposed. Pol $\eta$ was shown to act as a bridge between PCNA and the ubiquitinprotein ligase Rad18, and to favor the mono-ubiquitination of PCNA by Rad18 independently of its polymerase activity (Durando et al, 2013). The c-ter of Rev1 but not the catalytic activity, is necessary to recruit the TLS DNA polymerases $\eta, \kappa, \imath$ and $\zeta$ for DNA damage tolerance (Tissier et al, 2004). The Chk1-regulatory function of Pol $\kappa$ which is independent of its catalytic activity could help in understanding some recent observations from the literature: Human lymphoblastic Nalm6 cells engineered to express a catalytic dead Pol $\kappa$ mutant showed the same sensitivity to oxidative stress induced by hydrogen peroxide and menadione as Pol $\kappa$ wild type cells while Pol $\kappa$ knock-out counterpart were highly sensitive (Kanemaru et $a l, 2015)$. Temprine and colleagues have associated the increased expression of Pol $\kappa$ to drug 
resistance but without a high rate of mutagenesis. They propose a non-catalytic function of Pol $\kappa$ to explain the drug resistance (Temprine et al, 2020). Pol $\kappa$ can also protect forks against nascent DNA degradation and the polymerase activity is not essential to perform this task (Tonzi et al, 2018). We propose that the stabilization by Pol $\kappa$ of Chk1 could explain both the recovery of the stalled fork, the prevention of fork degradation and breaks accumulation (Forment et al, 2011; Murfuni et al, 2013; Thompson et al, 2012).

The maintenance of a basal replication checkpoint activity in unchallenged cells is an important concept that is reinforced with recent publications (Panagopoulos \& Altmeyer, 2020; Michelena et al, 2019). The idea presented by Panagopoulos and Altmeyer is that facing endogenous replication stress due to local impediments such as repeats, structured DNA or local dNTP pool decrease, cells adapt instead of arrest their cell cycle progression. They proposed a fine-tuned deceleration and brake release mechanism dependent on the ATR-Chk1 axis (Panagopoulos \& Altmeyer, 2020). Thus a constant basal activity of Chk1 is pre-requisite and Pol $\kappa$ could be an actor of this regulation as in response to huge replication stress the dependency on Pol $\kappa$ to restart stalled forks is less obvious (Tonzi et al, 2018).

Thus Pol $\kappa$ could act at stalled forks to maintain genome stability in several ways: insertion of nucleotides in front of lesions (TLS function), elongation of primers to allow the S-phase checkpoint activation (S-phase checkpoint associated function), and regulation of the abundance of Chk1 in the nucleus (Chk1 regulator). The first two roles depend on its polymerase activity whereas the third one does not (Fig 7).

In conclusion, besides the well-documented importance of the catalytic function of the DNA Pol $\kappa$ for translesion synthesis, stalled forks recovery, checkpoint activation or replication under low level of dNTP, this study unveils a unprecedented described DNA synthesisindependent regulatory function of Pol $\kappa$ to protect forks from degradation and maintain basal level activity of replication checkpoint. 


\section{Materials and methods}

\section{Cell culture and cell lines}

RKO, 293T, HCT116 Cells were cultured in DMEM/Glutamax supplemented 10\% FBS (GIBCO) and MRC5-SV in alpha-MEM /Glutamax with $10 \% \mathrm{SVF}$ (GIBCO) at $37^{\circ} \mathrm{C}$ in a humidified incubator in an atmosphere containing 5\% $\mathrm{CO}_{2}$ (Panasonic MCO-19AIC-PE). All cells were routinely checked for mycoplasma contamination using PlasmoTest ${ }^{\mathrm{TM}}$ Kit (InvivoGen).

\section{Drugs and cell culture supplement}

When indicated, cells were treated with hydroxyurea (Sigma-Aldrich), proteasome inhibitor MG132 (APExBIO), cycloheximide (Biosciences) for doses and time indicated in the figure legends. The dNTP analogs CldU and IdU (Sigma-Aldrich) were used as indicated in figures and the "DNA fibers assay" section of Materials and Methods.

\section{siRNA and plasmid transfections}

1.5-2 $\times 10^{6}$ cells were seeded $24 \mathrm{~h}$ before transfection with $45 \mathrm{nM}$ of siRNA using Lipofectamine RNAiMAX (Life Technologies). The following siRNA molecules used against 
the coding sequence of Pol $\kappa$ (Polк) (5'CCAAUAGACAAGCUGUGAU3' from SigmaAldrich), the 3'UTR of Pol $\kappa$ (Polк3') (5'ACUCCAGCCUGAAGAGCGA3' from SigmaAldrich), USP7 (5'CCCAAAUUAUUCCGCGGCAAA3' from Sigma-Aldrich), the coding sequence of Chk1 (5'GAAGCAGUCGCAGUGAAGA3' from Sigma-Aldrich), the 3'UTR of Chk1 (3'Chk1) (5'CUGgugAaUAUAGUGCUGCUA3' from Sigma-Aldrich), Polı (SMART pool 5'CCACAGUUGGUAUUAGUUA3'; 5'GCACUAUGGUCGUGAGAGU3'; 5'CGGGUCAUGUAUACAAUAA3'; 5'GAACAUCAGGCUUUAAUAG3' from Dharmacon), the 3'UTR of Poln (5'GCAAUGAGGGCCUUGAACA3' from sigma-Aldrich) and Rev1 (5'CAGCGCAUCUGUGCCAAAGAA3' from Sigma-Aldrich). For control, siRNA against luciferase and the catalytically inactive mutant of human Pol $\kappa$ (Dead Pol $\kappa-$ D198A and E199A) were previously described in Betous et al. (Bétous et al, 2013). The wild-type human Pol $\kappa$ coding sequence was cloned into the peGFP vector (peGFP-Kappa_WT). Transfections of 4 to $8 \mu \mathrm{g}$ of plasmids were carried out using JetPrime (Polyplus transfection) following the manufacturer's recommendations.

\section{Nuclear cell extracts, Western Blot and quantification}

Nuclear extracts were obtained using to the NE-PER ${ }^{\mathrm{TM}}$ Nuclear and cytoplasmic Extraction reagents kit (Thermo Scientific) according to the manufacturer's recommendations. Proteins were dosed by the Bradford's method (BioRad) and separated by SDS-PAGE (life technologies, NUPAGE ${ }^{\mathrm{TM}} 4-12 \%$ or $3-8 \%$ ). For immunoblotting, primary antibodies were incubated overnight at $4^{\circ} \mathrm{C}$ in TBS $1 \mathrm{X}$ with Tween $0.1 \%$. Secondary Peroxidase-coupled antibodies (Jackson Immuno Research, Life Technologies) were incubated at room temperature for $1 \mathrm{hr}$. Blots were detected by ECL plus Western Blotting substrate (Pierce) or ECL Bright Quantum (Diagomix) on BlueDevil ${ }^{\circledR}$ autoradiography film (Genesee Scientific) or under the ChemiDoc imaging system (BioRad). Primary antibodies were used at the 
following dilutions: Pol $\kappa$ (from Dr. T Nohmi 1/1000), Pol $\kappa$ (from Sigma HPA012035 $1 / 1000)$

Chk1 (Abcam ab32531 - 1/1000), Chk1-pS345 (Cell signaling 2348 -1/1000), ORC2 (MBL M055-3 - 1/1000), ORC4 (Transduction laboratories H83120, 1/500) MCM7 (Santa Cruz sc22782 - 1/1000), MCM2 (Abcam ab4461 - 1/2000), Actin (Millipore MAB1501 1/10000), Actinin (Millipore 05-384 - 1/2000), Fibrillarin (Sigma-Aldrich SAB4300633 - 1/1000), p53 (BDSciences 554294 - 1/2000). Where indicated, proteins were quantified using ImageJ software.

\section{RNA extraction and quantitative PCR Analysis}

Total RNA was extracted from cell using RNeasy® kit (Qiagen) according to the supplier's instructions, then $1 \mu \mathrm{g}$ of total RNA was reverse transcribed into cDNA using Superscript II (Invitrogen) according to the manufacturer's recommendations. Duplicate quantitative PCR assays were run on StepOne Real Time system from Applied Biosystems with TaqMan Universal Master Mix II and specific probes from assay on demand (Applied Biosystems). Three house-keeping genes (ACTIN B, YWHAZ, GAPDH) were also amplified and used as references. The relative amount of each mRNA level was normalized to the control condition and calculated using the $\Delta \Delta \mathrm{CT}$ method.

\section{EDU incorporation, QIBC and Chk1 immunofluorescence}

For immunostaining, transfected cell lines used for immunofluorescence were plated on an 8well chamber slide (Lab-Tek $\left.{ }^{\circledR}\right)$. When EdU incorporation was performed, it was added 15 or 30 minutes to parallel cultures growing exponentially in culture media containing at final concentration of $10 \mu \mathrm{M}$. Fixation was done with a $4 \%$ PFA/PBS solution for $10 \mathrm{~min}$, then permeabilization and saturation step was performed in PBS $1 \mathrm{X}$ containing BSA 3\% and Triton $0.1 \mathrm{X}$ for $30 \mathrm{~min}$ (PBS-Triton/BSA). Detection of EdU was performed prior to 
incubation with the primary antibodies using the Click-iT ${ }^{\mathrm{TM}}$ Plus EdU Alexa Fluor ${ }^{\mathrm{TM}} 488$ Imaging Kit according to the manufacturer's instructions (Thermo-Fisher Scientific). Chk1 primary antibody (Abcam ab32531 - 1/1000) was diluted in PBS-Triton/BSA and incubated 1 hour at room temperature. The 8-well chambers slides were washed three times with PBS 1X and incubated in PBS-Triton/BSA containing fluorescent secondary antibodies at 1/800 (Alexa fluorophores, Life Technologies) for $30 \mathrm{~min}$. Three washes were performed and nuclei were stained with DAPI. For mounting the slides, the Prolong Diamond Antifade reagent (Thermo-Fischer Scientific) was used. 10 to 20 images were acquired randomly. After acquisition, the images were processed for automated analysis with the Cell Profiler image analysis software. DAPI signal was used for segmentation of the nuclei according to intensity threshold, generating a mask which identified each individual nucleus as an individual object. This mask was applied to quantify pixel intensities in the different channels for each individual cell/object. The values quantified for EdU and DAPI staining per cell were graph plotted by dual-parameter (EdU vs DNA) generating diagrams in a flow-cytometry-like fashion (QIBC Quantitative-based image Cytometry) for each cell condition. This approach allows the assignment of cells to G1, S or G2/M phases.

\section{Microscope image acquisition and analysis.}

Image acquisition of multiple random fields was carried out on a wide field Nikon Eclipse NiE microscope equipped with x63 oil immerged objective Nikon Plan Apo $1.4 \lambda$ using a C-mos DsQi2 camera driven by NIS-Elements AR software. Fluorescence quantifications were performed with Cell Profiler2.1.1. Images were assembled with Adobe photoshop ${ }^{\circledR}$ and Adobe Illustrator ${ }^{\circledR}$.

\section{DNA fiber assay}


Cells were pulse-labelled with $50 \mu \mathrm{M}$ ldU for 20 minutes, washed, then treated with $\mathrm{HU}$ $(1 \mathrm{mM})$ for 1 hour. After removal of HU and washing, ongoing DNA fibers were labelled in medium containing CldU at $100 \mu \mathrm{M}$ final for 30 minutes. The cells were harvested, lysed in $200 \mathrm{mM}$ Tris- $\mathrm{HCl} \mathrm{pH} 7.4,0.5 \%$ SDS, $50 \mathrm{mM}$ EDTA, and the DNA fibers were spread on glass slides. The slides were incubated with $0.5 \mathrm{mg} / \mathrm{ml}$ pepsin in $30 \mathrm{mM} \mathrm{HCl}$ at $37^{\circ} \mathrm{C}$ for 20 minutes, the DNA was denatured in $2.5 \mathrm{M} \mathrm{HCl}$ for 1 hour and blocked with $1 \%$ BSA containing $0.1 \%$ Tween 20 in PBS1X. The nucleotide analogues were detected with primary antibodies against CldU (Novus), and IdU (BD Biosciences) and the secondary antibodies anti-rat Alexa Fluor 555 and anti-mouse Alexa Fluor 488 (Thermo Fischer Scientific). Coverslips were mounted on slides using the Prolong Diamond Antifade reagent (ThermoFisher Scientific). Images were captured with a Nikon Ni-E microscope and a DS-Qi2 camera equipped with a $20 \mathrm{X}$ objective and lengths of CldU tracks were measured with NIS-Elements AR imaging software.

\section{Statistical analysis}

GraphPad Prism version 5.03 for Windows was used for statistical analysis. Differences were considered statistically significant at $P<0.05$. Data are reported as the medians with $25 \%$ $75 \%$ interquartile ranges or as the means \pm SEM. Results were compared by 2-tailed Student's $t$ test for two groups or a Mann-Whitney nonparametric test as written in legends.

\section{Acknowledgements}

We thank Drs V Bergoglio and S Manenti from the Cancer Research Center of Toulouse for the critical reading of the manuscript and helpful discussions. We thank Dr Takehiko Nohmi (National Institute of Health Sciences, Japan) and Dr Masami Yamada (National Institute of Health Sciences, Japan) for the Rabbit anti-Polк antibodies. M Dall'Osto is financially supported by the Region Languedoc Roussillon Midi Pyrénées /INSERM fellowship (U1037- 
R16068BB-Region). Work was supported by funding from INCa-PLBIO 2016, ANR PRC 2016, Labex Toucan and La Ligue contre le Cancer (Equipe labellisée) to JSH, as well as Ligue Régionale grants RAB17004BBA to MJP.

\section{Author contribution}

NV performed the rescue experiments with the GFP-Pol Kappa vector. MJP, MD and LP performed experiments. MD and MJP conceived the study design. MD and LP defined experimental approaches. MD carried out data analysis with the supervision of MJP. MD, MJP and JSH wrote the manuscript. JSH and MJP acquired the fundings.

\section{Conflicts of Interest}

The authors have no financial or other conflict of interest to declare.

Bibliography

Alonso-de Vega I, Martín Y \& Smits VAJ (2014) USP7 controls Chk1 protein stability by direct deubiquitination. Cell Cycle Georget Tex 13: 3921-3926

Barnes RP, Hile SE, Lee MY \& Eckert KA (2017) DNA polymerases eta and kappa exchange with the polymerase delta holoenzyme to complete common fragile site synthesis. DNA Repair 57: 111

Bavoux C, Leopoldino AM, Bergoglio V, O-Wang J, Ogi T, Bieth A, Judde J-G, Pena SDJ, Poupon M-F, Helleday $T$, et al (2005) Up-regulation of the error-prone DNA polymerase \{kappa\} promotes pleiotropic genetic alterations and tumorigenesis. Cancer Res 65: 325-330

Bergoglio V, Boyer A-S, Walsh E, Naim V, Legube G, Lee MYWT, Rey L, Rosselli F, Cazaux C, Eckert KA, et al (2013) DNA synthesis by Pol $\eta$ promotes fragile site stability by preventing underreplicated DNA in mitosis. J Cell Biol 201: 395-408

Bétous R, Pillaire M-J, Pierini L, van der Laan S, Recolin B, Ohl-Séguy E, Guo C, Niimi N, Grúz P, Nohmi $\mathrm{T}$, et al (2013) DNA polymerase $\mathrm{k}$-dependent DNA synthesis at stalled replication forks is important for CHK1 activation. EMBO J 32: 2172-2185

Bournique E, Dall'Osto M, Hoffmann J-S \& Bergoglio V (2018) Role of specialized DNA polymerases in the limitation of replicative stress and DNA damage transmission. Mutat Res 808: 62-73

Cassidy KB, Bang S, Kurokawa M \& Gerber SA (2020) Direct regulation of Chk1 protein stability by E3 ubiquitin ligase HUWE1. FEBS J 287: 1985-1999 
Cheng Y-C \& Shieh S-Y (2018) Deubiquitinating enzyme USP3 controls CHK1 chromatin association and activation. Proc Natl Acad Sci U S A 115: 5546-5551

David L, Fernandez-Vidal A, Bertoli S, Grgurevic S, Lepage B, Deshaies D, Prade N, Cartel M, Larrue C, Sarry J-E, et al (2016) CHK1 as a therapeutic target to bypass chemoresistance in AML. Sci Signal 9: ra90

Despras E, Daboussi F, Hyrien O, Marheineke K \& Kannouche PL (2010) ATR/Chk1 pathway is essential for resumption of DNA synthesis and cell survival in UV-irradiated XP variant cells. Hum Mol Genet 19: 1690-1701

Durando M, Tateishi S \& Vaziri C (2013) A non-catalytic role of DNA polymerase $\eta$ in recruiting Rad18 and promoting PCNA monoubiquitination at stalled replication forks. Nucleic Acids Res 41: 3079-3093

Forment JV, Blasius M, Guerini I \& Jackson SP (2011) Structure-specific DNA endonuclease Mus81/Eme1 generates DNA damage caused by Chk1 inactivation. PloS One 6: e23517

Gagou ME, Zuazua-Villar P \& Meuth M (2010) Enhanced H2AX phosphorylation, DNA replication fork arrest, and cell death in the absence of Chk1. Mol Biol Cell 21: 739-752

González Besteiro MA, Calzetta NL, Loureiro SM, Habif M, Bétous R, Pillaire M-J, Maffia A, Sabbioneda S, Hoffmann J-S \& Gottifredi V (2019) Chk1 loss creates replication barriers that compromise cell survival independently of excess origin firing. EMBO J 38: e101284

González Besteiro MA \& Gottifredi V (2015) The fork and the kinase: a DNA replication tale from a CHK1 perspective. Mutat Res Rev Mutat Res 763: 168-180

Gottifredi V, Karni-Schmidt O, Shieh SS \& Prives C (2001) p53 down-regulates CHK1 through p21 and the retinoblastoma protein. Mol Cell Biol 21: 1066-1076

Guervilly J-H, Renaud E, Takata M \& Rosselli F (2011) USP1 deubiquitinase maintains phosphorylated CHK1 by limiting its DDB1-dependent degradation. Hum Mol Genet 20: 2171-2181

Guo C, Kosarek-Stancel JN, Tang T-S \& Friedberg EC (2009) Y-family DNA polymerases in mammalian cells. Cell Mol Life Sci CMLS 66: 2363-2381

Hakura A, Sui H, Sonoda J, Matsuda T \& Nohmi T (2019) DNA polymerase kappa counteracts inflammation-induced mutagenesis in multiple organs of mice. Environ Mol Mutagen 60: $320-330$

Hromas R, Williamson EA, Fnu S, Lee Y-J, Park S-J, Beck BD, You J-S, Leitao A, Laitao A, Nickoloff JA, et al (2012) Chk1 phosphorylation of Metnase enhances DNA repair but inhibits replication fork restart. Oncogene 31: 4245-4254

Kaneko YS, Watanabe N, Morisaki H, Akita H, Fujimoto A, Tominaga K, Terasawa M, Tachibana A, Ikeda K, Nakanishi M, et al (1999) Cell-cycle-dependent and ATM-independent expression of human Chk1 kinase. Oncogene 18: 3673-3681

Kanemaru Y, Suzuki T, Niimi N, Grúz P, Matsumoto K, Adachi N, Honma M \& Nohmi T (2015) Catalytic and non-catalytic roles of DNA polymerase $\mathrm{k}$ in the protection of human cells against genotoxic stresses. Environ Mol Mutagen 56: 650-662 
Lam MH, Liu Q, Elledge SJ \& Rosen JM (2004) Chk1 is haploinsufficient for multiple functions critical to tumor suppression. Cancer Cell 6: 45-59

Lange SS, Takata K \& Wood RD (2011) DNA polymerases and cancer. Nat Rev Cancer 11: 96-110

Lecona E \& Fernandez-Capetillo O (2018) Targeting ATR in cancer. Nat Rev Cancer 18: 586-595

Leung-Pineda V, Huh J \& Piwnica-Worms H (2009) DDB1 targets Chk1 to the Cul4 E3 ligase complex in normal cycling cells and in cells experiencing replication stress. Cancer Res 69: 2630-2637

Liu Q, Guntuku S, Cui XS, Matsuoka S, Cortez D, Tamai K, Luo G, Carattini-Rivera S, DeMayo F, Bradley $A$, et al (2000) Chk1 is an essential kinase that is regulated by Atr and required for the G(2)/M DNA damage checkpoint. Genes Dev 14: 1448-1459

Lone S, Townson SA, Uljon SN, Johnson RE, Brahma A, Nair DT, Prakash S, Prakash L \& Aggarwal AK (2007) Human DNA polymerase kappa encircles DNA: implications for mismatch extension and lesion bypass. Mol Cell 25: 601-614

López-Contreras AJ, Gutierrez-Martinez P, Specks J, Rodrigo-Perez S \& Fernandez-Capetillo O (2012) An extra allele of Chk1 limits oncogene-induced replicative stress and promotes transformation. J Exp Med 209: 455-461

Mansilla SF, Bertolin AP, Bergoglio V, Pillaire M-J, González Besteiro MA, Luzzani C, Miriuka SG, Cazaux C, Hoffmann J-S \& Gottifredi V (2016) Cyclin Kinase-independent role of p21CDKN1A in the promotion of nascent DNA elongation in unstressed cells. eLife 5

McVey M, Khodaverdian VY, Meyer D, Cerqueira PG \& Heyer W-D (2016) Eukaryotic DNA Polymerases in Homologous Recombination. Annu Rev Genet 50: 393-421

Michelena J, Gatti M, Teloni F, Imhof R \& Altmeyer M (2019) Basal CHK1 activity safeguards its stability to maintain intrinsic S-phase checkpoint functions. J Cell Biol 218: 2865-2875

Murfuni I, Basile G, Subramanyam S, Malacaria E, Bignami M, Spies M, Franchitto A \& Pichierri P (2013) Survival of the replication checkpoint deficient cells requires MUS81-RAD52 function. PLoS Genet 9: e1003910

Ogi T, Limsirichaikul S, Overmeer RM, Volker M, Takenaka K, Cloney R, Nakazawa Y, Niimi A, Miki Y, Jaspers NG, et al (2010) Three DNA polymerases, recruited by different mechanisms, carry out NER repair synthesis in human cells. Mol Cell 37: 714-727

Ohashi E, Ogi T, Kusumoto R, Iwai S, Masutani C, Hanaoka F \& Ohmori H (2000) Error-prone bypass of certain DNA lesions by the human DNA polymerase kappa. Genes Dev 14: 1589-1594

Panagopoulos A \& Altmeyer M (2020) The Hammer and the Dance of Cell Cycle Control. Trends Biochem Sci

Peng C, Chen Z, Wang S, Wang H-W, Qiu W, Zhao L, Xu R, Luo H, Chen Y, Chen D, et al (2016) The Error-Prone DNA Polymerase $\mathrm{k}$ Promotes Temozolomide Resistance in Glioblastoma through Rad17-Dependent Activation of ATR-Chk1 Signaling. Cancer Res 76: 2340-2353

Petermann E, Maya-Mendoza A, Zachos G, Gillespie DAF, Jackson DA \& Caldecott KW (2006) Chk1 requirement for high global rates of replication fork progression during normal vertebrate $S$ phase. Mol Cell Biol 26: 3319-3326 
Petermann E, Woodcock M \& Helleday T (2010) Chk1 promotes replication fork progression by controlling replication initiation. Proc Natl Acad Sci U S A 107: 16090-16095

Pillaire M-J, Betous R, Conti C, Czaplicki J, Pasero P, Bensimon A, Cazaux C \& Hoffmann J-S (2007) Upregulation of error-prone DNA polymerases beta and kappa slows down fork progression without activating the replication checkpoint. Cell Cycle Georget Tex 6: 471-477

Pillaire M-J, Bétous R \& Hoffmann J-S (2014) Role of DNA polymerase $\mathrm{k}$ in the maintenance of genomic stability. Mol Cell Oncol 1: e29902

Sarkies P, Reams C, Simpson L \& Sale JE (2010) Epigenetic instability due to defective replication of structured DNA. Mol Cell 40: 703-713

Smits VAJ \& Gillespie DA (2015) DNA damage control: regulation and functions of checkpoint kinase 1. FEBS J 282: 3681-3692

Speroni J, Federico MB, Mansilla SF, Soria G \& Gottifredi V (2012) Kinase-independent function of checkpoint kinase 1 (Chk1) in the replication of damaged DNA. Proc Natl Acad Sci U S A 109: 7344-7349

Stancel JNK, McDaniel LD, Velasco S, Richardson J, Guo C \& Friedberg EC (2009) Polk mutant mice have a spontaneous mutator phenotype. DNA Repair 8: 1355-1362

Técher H, Koundrioukoff S, Carignon S, Wilhelm T, Millot GA, Lopez BS, Brison O \& Debatisse M (2016) Signaling from Mus81-Eme2-Dependent DNA Damage Elicited by Chk1 Deficiency Modulates Replication Fork Speed and Origin Usage. Cell Rep 14: 1114-1127

Técher H, Koundrioukoff S, Nicolas A \& Debatisse M (2017) The impact of replication stress on replication dynamics and DNA damage in vertebrate cells. Nat Rev Genet 18: 535-550

Temprine K, Campbell NR, Huang R, Langdon EM, Simon-Vermot T, Mehta K, Clapp A, Chipman M \& White RM (2020) Regulation of the error-prone DNA polymerase Polk by oncogenic signaling and its contribution to drug resistance. Sci Signal 13

Thompson R, Montano R \& Eastman A (2012) The Mre11 nuclease is critical for the sensitivity of cells to Chk1 inhibition. PloS One 7: e44021

Tissier A, Kannouche P, Reck M-P, Lehmann AR, Fuchs RPP \& Cordonnier A (2004) Co-localization in replication foci and interaction of human $\mathrm{Y}$-family members, DNA polymerase pol eta and REVI protein. DNA Repair 3: 1503-1514

Toledo LI, Altmeyer M, Rask M-B, Lukas C, Larsen DH, Povlsen LK, Bekker-Jensen S, Mailand N, Bartek J \& Lukas J (2013) ATR prohibits replication catastrophe by preventing global exhaustion of RPA. Cell 155: 1088-1103

Tonzi P \& Huang TT (2019) Role of Y-family translesion DNA polymerases in replication stress: Implications for new cancer therapeutic targets. DNA Repair 78: 20-26

Tonzi P, Yin Y, Lee CWT, Rothenberg E \& Huang TT (2018) Translesion polymerase kappa-dependent DNA synthesis underlies replication fork recovery. eLife 7

Tsao W-C \& Eckert KA (2018) Detours to Replication: Functions of Specialized DNA Polymerases during Oncogene-induced Replication Stress. Int J Mol Sci 19 
Tu Y, Liu H, Zhu X, Shen H, Ma X, Wang F, Huang M, Gong J, Li X, Wang Y, et al (2017) Ataxin-3 promotes genome integrity by stabilizing Chk1. Nucleic Acids Res 45: 4532-4549

Walsh E, Wang X, Lee MY \& Eckert KA (2013) Mechanism of replicative DNA polymerase delta pausing and a potential role for DNA polymerase kappa in common fragile site replication. $J$ Mol Biol 425: 232-243

Williams HL, Gottesman ME \& Gautier J (2012) Replication-independent repair of DNA interstrand crosslinks. Mol Cell 47: 140-147

Yang Y, Gao Y, Mutter-Rottmayer L, Zlatanou A, Durando M, Ding W, Wyatt D, Ramsden D, Tanoue Y, Tateishi S, et al (2017) DNA repair factor RAD18 and DNA polymerase Polk confer tolerance of oncogenic DNA replication stress. J Cell Biol 216: 3097-3115

Zeman MK \& Cimprich KA (2014) Causes and consequences of replication stress. Nat Cell Biol 16: 2-9

Zhang Y \& Hunter T (2014) Roles of Chk1 in cell biology and cancer therapy. Int J Cancer 134: 10131023

Zhang Y-W, Brognard J, Coughlin C, You Z, Dolled-Filhart M, Aslanian A, Manning G, Abraham RT \& Hunter T (2009) The F box protein Fbx6 regulates Chk1 stability and cellular sensitivity to replication stress. Mol Cell 35: 442-453

Zhang Y-W, Otterness DM, Chiang GG, Xie W, Liu Y-C, Mercurio F \& Abraham RT (2005) Genotoxic stress targets human Chk1 for degradation by the ubiquitin-proteasome pathway. Mol Cell 19: $607-618$ 
Figure 1

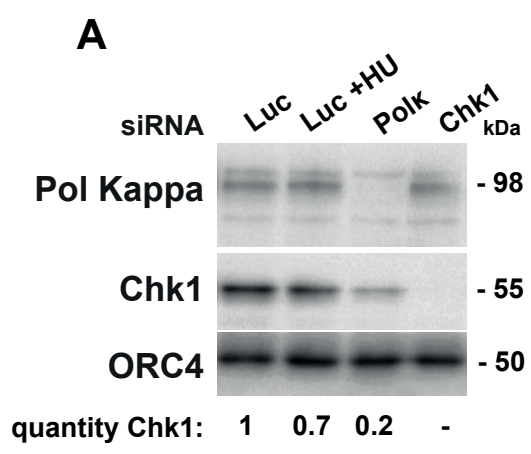

D HCT116

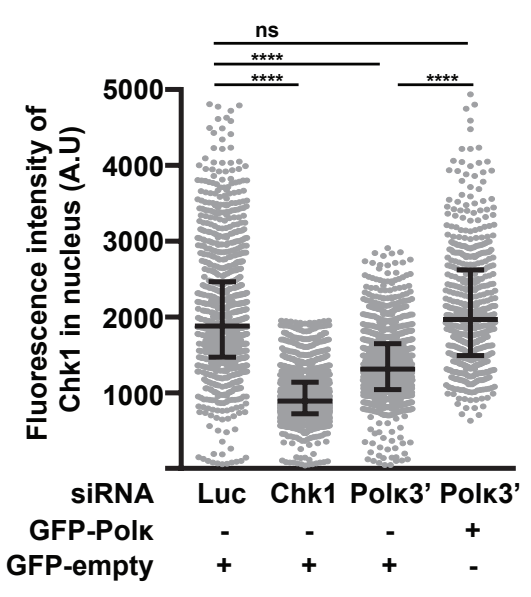

$\mathbf{F}$

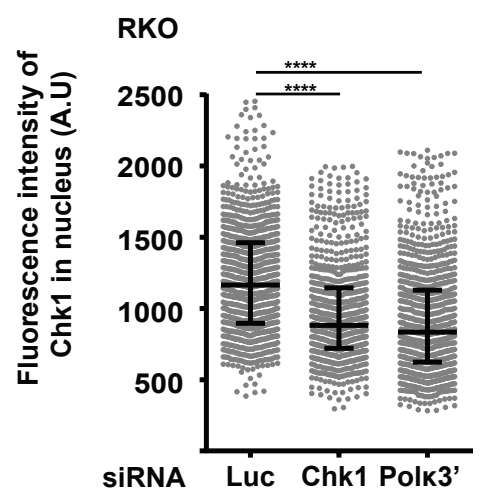

B

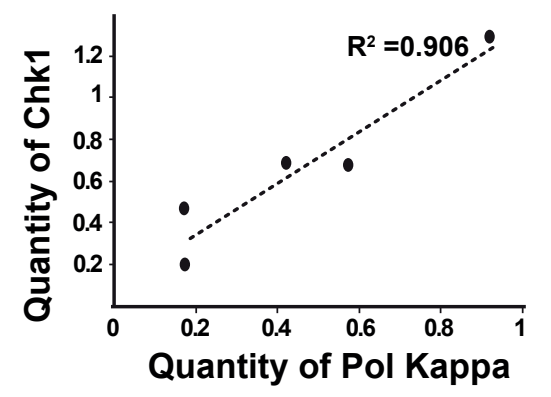

C $\quad$ MRC5-SV

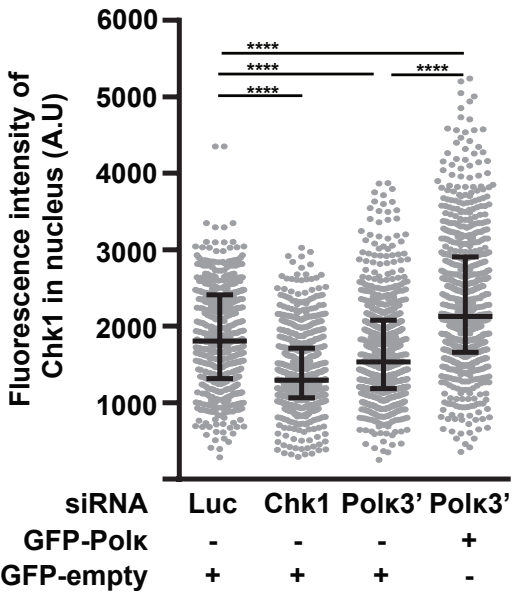

E

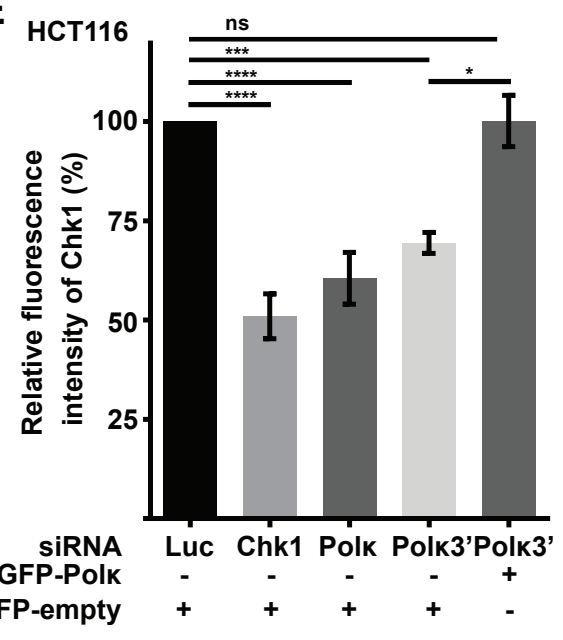

G

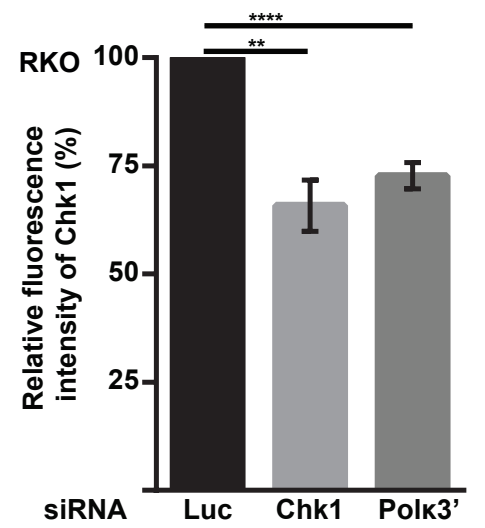


Figure 2
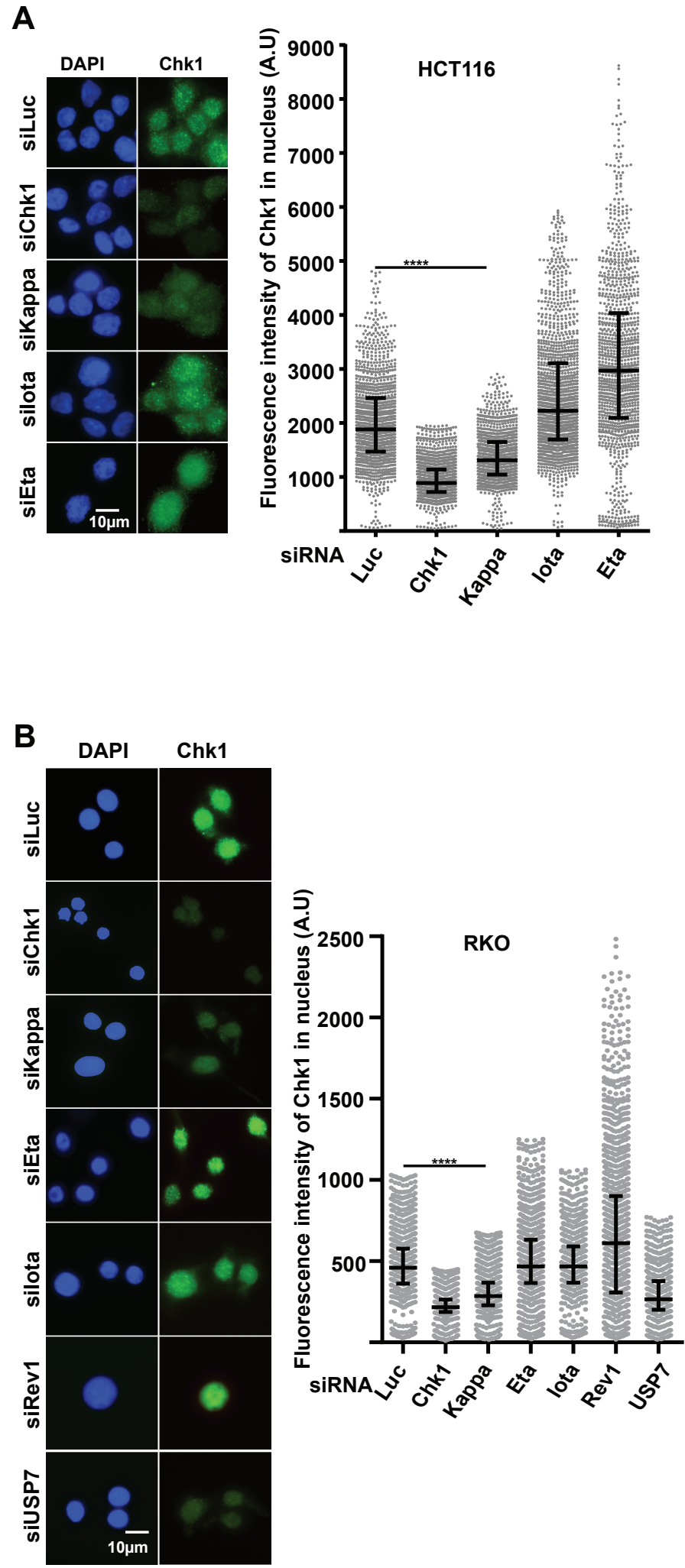
Figure 3

A
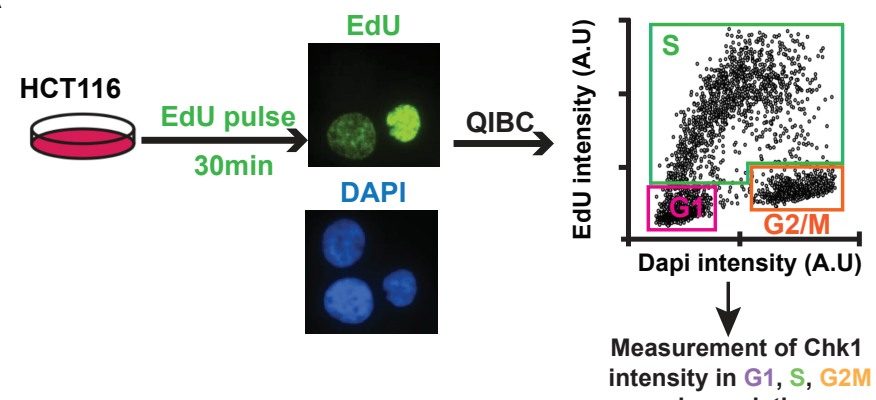

B

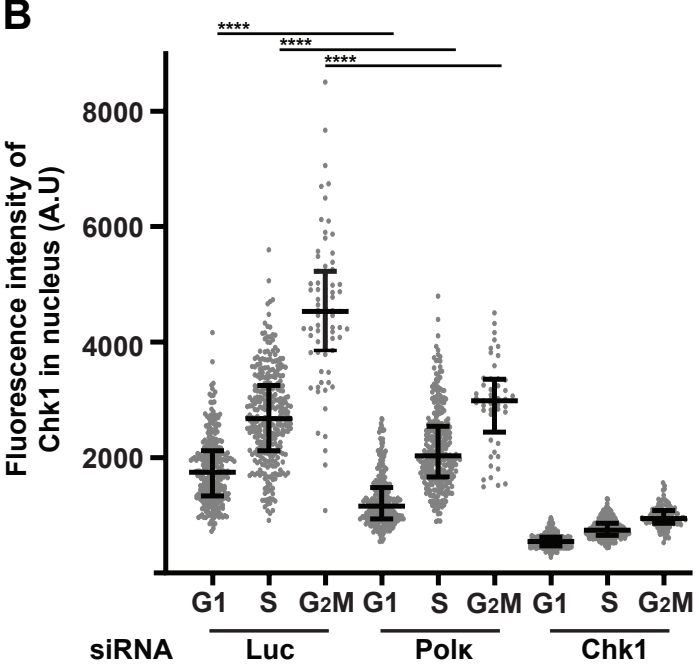


A

RKo

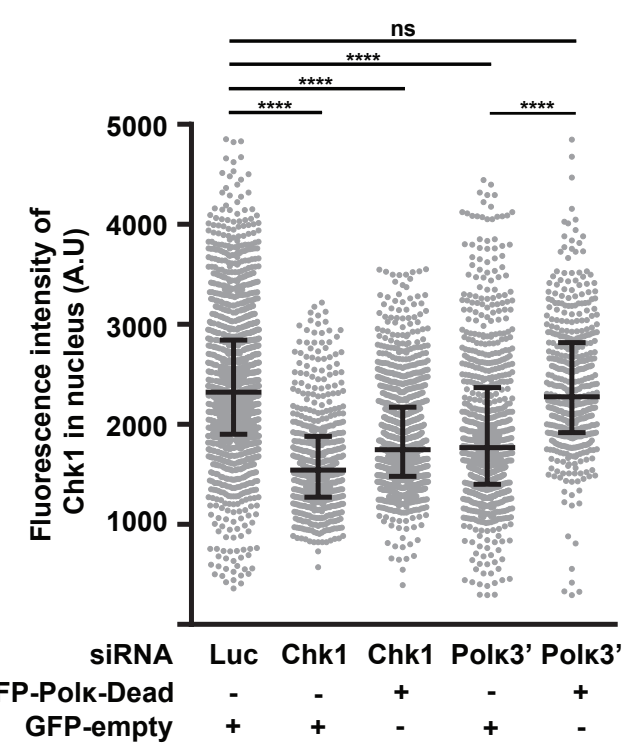

Figure 4

B HCT116

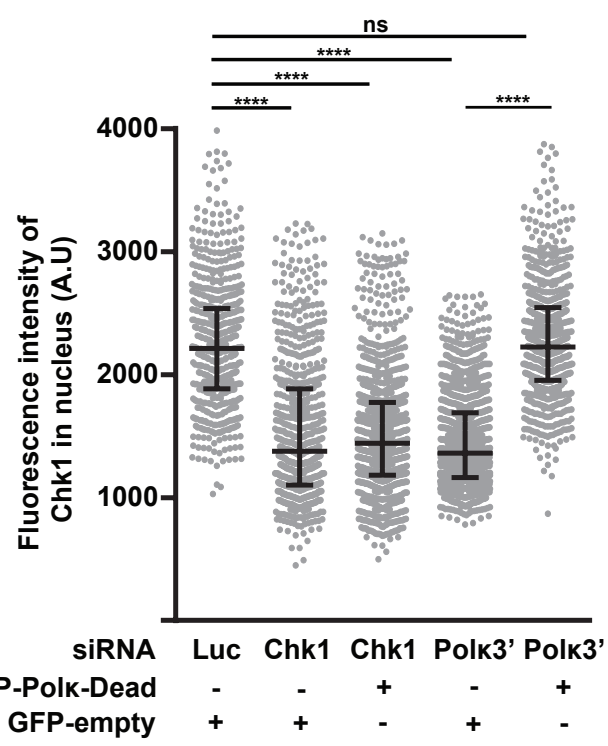


Figure 5

A

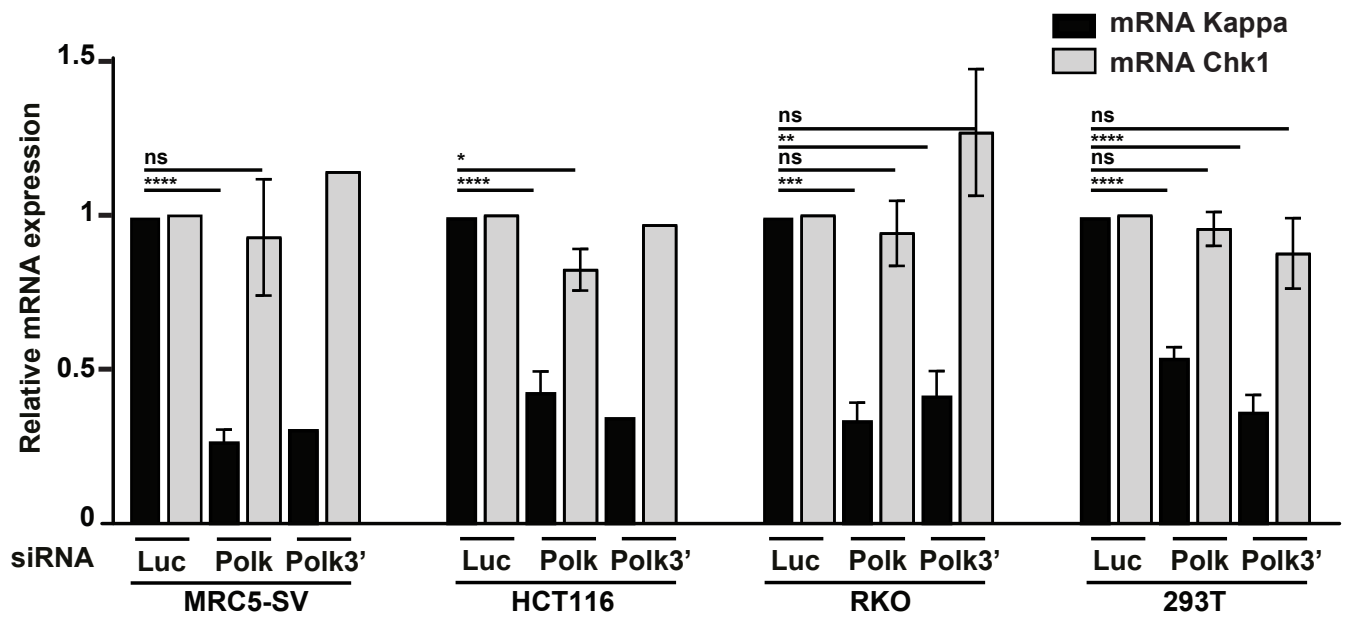

B

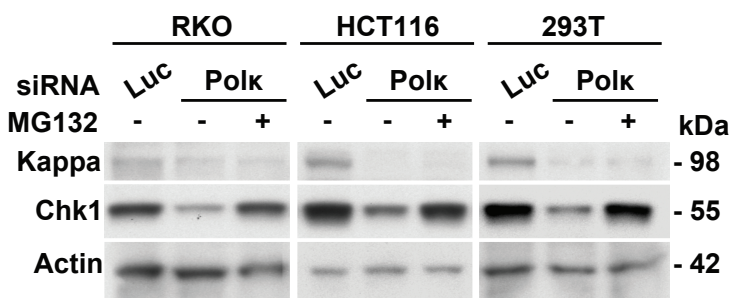

C

HCT116

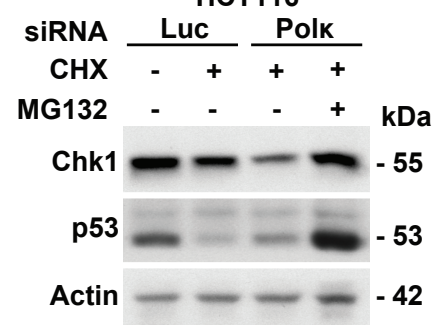


Figure 6

A

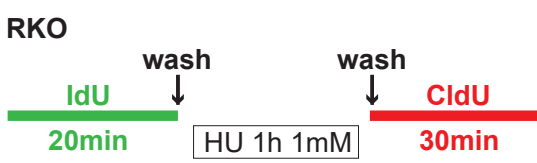

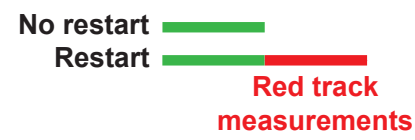

B ns

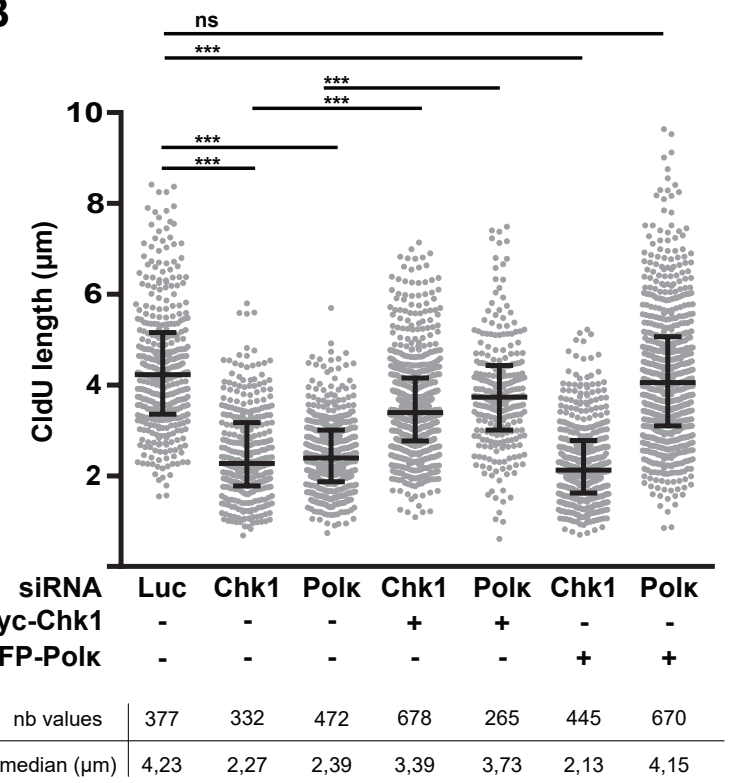


Figure 7

\section{Pol Kappa}

\section{Catalytic activities}

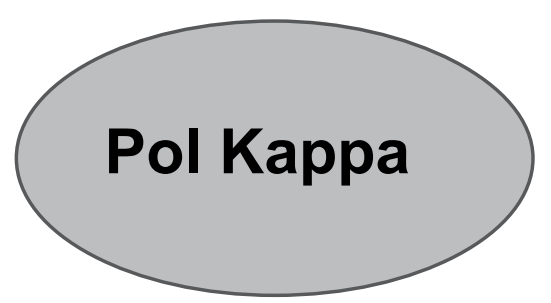

- Translesion synthesis

- Replication of regions containing repeats

- Replication under low level of dNTP

- Fork recovery

Non-catalytic activities

- Checkpoint activation

Chk1

Stability

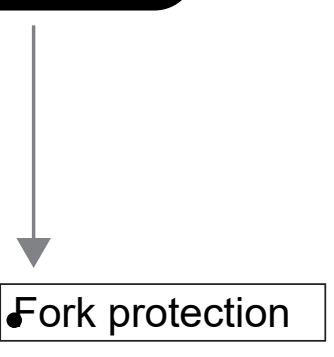




\section{Figure 1: Chk1 protein level is reduced in the nucleus of mammalian cells depleted for Pol $\mathrm{K}$}

(A) Western blot analysis of Chk1 and Pol $\kappa$ in MRC5-SV nuclear extracts $48 \mathrm{~h}$ after transfection with a control (Luc), Pol $\kappa$ (Polk) or Chk1 (Chk1) siRNA. Cells were untreated or treated with $1 \mathrm{mM}$ HU for $1 \mathrm{~h}$. ORC4 is shown as a proteinloading control. Quantification of Chk1 is relative to siLuc condition. (B) Relative Chk1 or Pol Kappa protein levels in siPolk nuclear extracts were normalized to siLuc condition (quantity of Chk1, quantity Pol of Kappa respectively) and data from 5 independent experiments in MRC-SV are plotted. The regression curve (dashed line) and R-square are shown. MRC5-SV (C), HCT116 (D) and RKO (F) cells were co-transfected with the indicated siRNAs and a vector expressing either GFP-empty or GFP-Pol $\kappa$. The fluorescence intensity of Chk1 was quantified in each nucleus. Medians with $25 \%$ and $75 \%$ interquartile ranges were represented. $\left({ }^{* * *} p=0.001 ;{ }^{* * * *} p<0.0001\right.$; Mann-Whitney test). $A \cdot U=$ arbitrary units. $n s=$ not significant. Relative fluorescence intensity of Chk1 in nuclei of HCT116 (E) and RKO (G) cells transfected with the indicated siRNAs (G) or both with a vector expressing either GFP-Pol $\kappa$ or GFPempty (E). Values are the mean ( \pm SEM) of medians of three or four independent experiments. Relative fluorescence intensity was adjusted to siLuc condition. $\left({ }^{*} p<0.05 ;{ }^{* *} p<0.01 ;{ }^{* * * *} p<0.0001 ;\right.$ t-test $) . n s=$ not significant.

\section{Figure 2: Among the Y-DNA polymerase family, only the Pol $\kappa$ depletion causes a Chk1 nuclear drop}

Representative images and quantification of Chk1 immunostaining (green). HCT116 (A) and RKO (B) cells were transfected with the indicated siRNAs and DNA was stained with DAPI. The fluorescence intensity of Chk1 was quantified in each nucleus. Medians with $25 \%$ and $75 \%$ interquartile ranges were presented. ( ${ }^{* * * *} p<0.0001$; MannWhitney test). Scale bar, $10 \mu \mathrm{m}$. A.U = arbitrary units.

\section{Figure 3: The Pol k-dependent Chk1 downregulation is not due to cycle arrest in G1}

(A) Schematic representation of pulse-EdU labelling experiment. HCT116 Cells were transfected with control (Luc), Pol $\kappa$ (Polk) or Chk1 (Chk1) siRNA. 48h after transfection, asynchronous cells were pulse-labelled with EdU for 30 min $(10 \mu \mathrm{M})$. Incorporated EdU was coupled to Alexa 488 in click-it reaction and DNA was stained with DAPI. EdU/DAPI dot plot shows the cell cycle distribution. (B) The fluorescence intensity of Chk1 was quantified in each nucleus of each cellular subpopulation transfected with indicated siRNA. Medians with $25 \%$ and $75 \%$ interquartile ranges were represented. $A . U=$ arbitrary units.

\section{Figure 4: Pol $\kappa$ controls the Chk1 pool independently of its DNA synthesis activity}

Quantification of Chk1 immunostaining in RKO (A) and HCT116 (B) cells co-transfected with the indicated siRNAs and with a control vector expressing GFP-empty or GFP-Polk-Dead. 48h after transfection, the fluorescence intensity of Chk1 was quantified in each nucleus. Medians with $25 \%$ and $75 \%$ interquartile ranges were represented $\left({ }^{* * * *} \mathrm{p}<0.0001 ;\right.$ Mann-Whitney test). A.U = arbitrary units. $\mathrm{ns}=$ not significant.

\section{Figure 5: Pol $\kappa$ protects Chk1 from degradation}

(A) Transcripts levels analysis of Pol $\kappa$ and Chk1 genes by RT-qPCR in MRC5-SV, HCT116, RKO and 293T cells transfected with siRNA against the $3^{\prime} U T R$ of Pol $\kappa$ (Polk3'), the coding sequence of Pol $\kappa$ (Polk). Relative expressions were normalized to siLuc condition. Values are the mean $( \pm S E M)$ of medians of independent experiments. $\left({ }^{*} p<0.05\right.$; $\left({ }^{* *} p<0.01 ;{ }^{* * *} p<0.001 ;{ }^{* * *} \mathrm{p}<0.0001 ; \mathrm{t}\right.$-test) ns = not significant. (B) Western Blot analysis of Chk1 in RKO, HCT116 and $293 \mathrm{~T}$ cells. $48 \mathrm{~h}$ after transfection with a control siRNA (Luc) or Pol $\kappa$ siRNA (Polk), cells were treated or not with MG132 $(20 \mu \mathrm{M})$ for $4 \mathrm{~h}$ just after transfection then $6 \mathrm{~h}$ before to harvest. Actin is shown as a protein-loading control. (C) Western Blot analysis of Chk1 in HCT116 cells extracts. 48h after transfection with indicated siRNA cells were

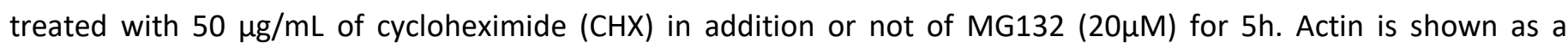
protein-loading control. 


\section{Figure 6: The replication defects associated with Pol $\kappa$ loss can be restored by Chk1 ectopic expression}

(A) Schematic representation of experimental DNA fiber labeling. RKO cells were co-transfected with the indicated siRNAs and a vector expressing either GFP-empty (-), GFP-Pol א (GFP- Polk) or myc-Chk1. 48h later, ongoing DNA replication forks were labeled with IdU (green tracks) for $20 \mathrm{~min}$, treated with $\mathrm{HU} 1 \mathrm{mM}$ during $1 \mathrm{~h}$ and then labelled with CldU (red tracks) during $30 \mathrm{~min}$. (B) The length of CldU tracks were measured and the values of two independent experiments were pooled and plotted. The number of CldU tracks measured and the medians of their lengths are indicated in the table. Medians with $25 \%$ and $75 \%$ interquartile ranges are represented $(* * * p=0.001$; $* * * p<0.001 ;$ Mann-Whitney test). ns = not significant.

\section{Figure 7: Working model}

Under physiological conditions, the DNA polymerase activity of Pol $\kappa$ is required to perform translesion synthesis, to replicate regions of the genome that contain repetitive sequences or local dNTP imbalance, to overcome fork stalling due to endogenous impediments and to participate in the S-phase checkpoint activation. In addition, the noncatalytic function of Pol $\kappa$ may be fundamental to protect forks from degradation and to stabilize Chk1 which in turn acts to coordinate the response to fork stalling. 


\section{Supplemental Figure1}

A

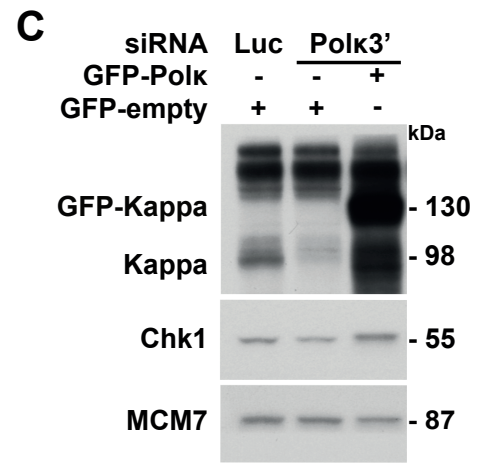

$E$

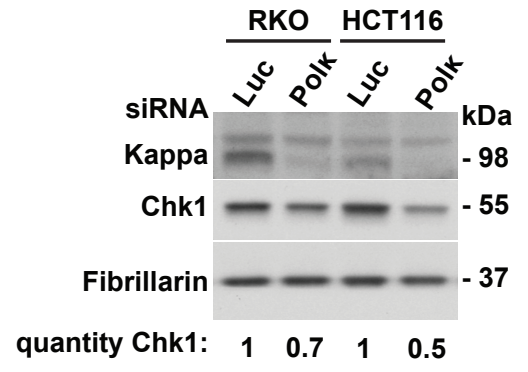

B

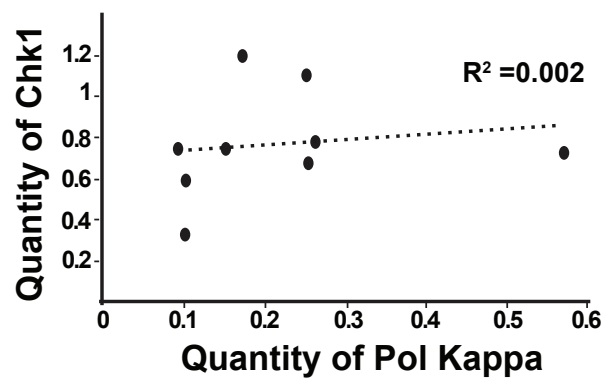

D

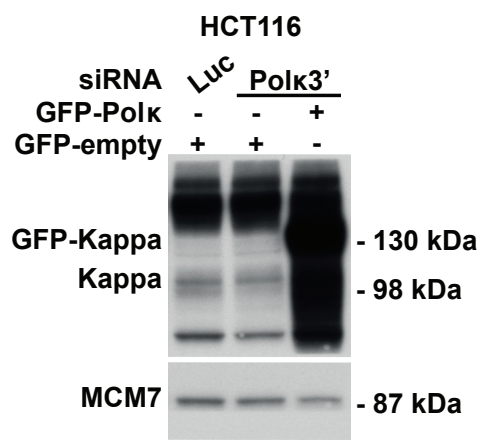

MCM7 ---87 kDa

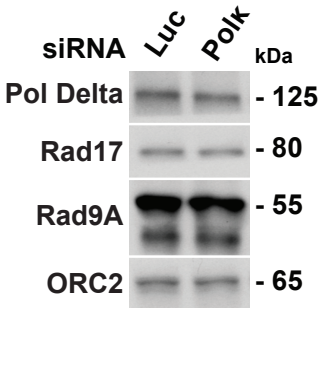

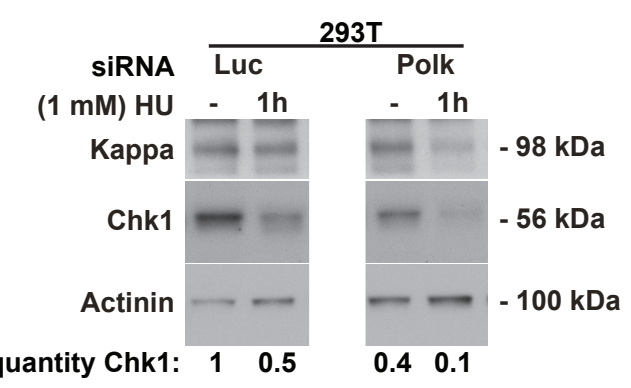




\section{Supplemental Figure 2}

A

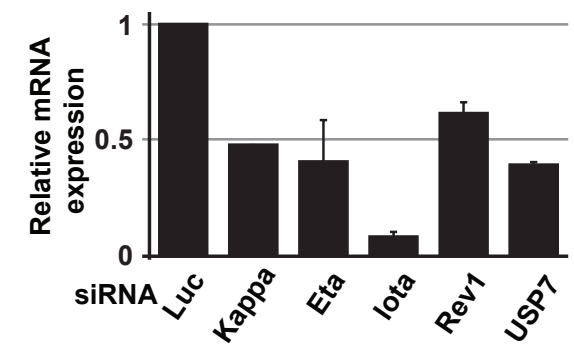

B RKO

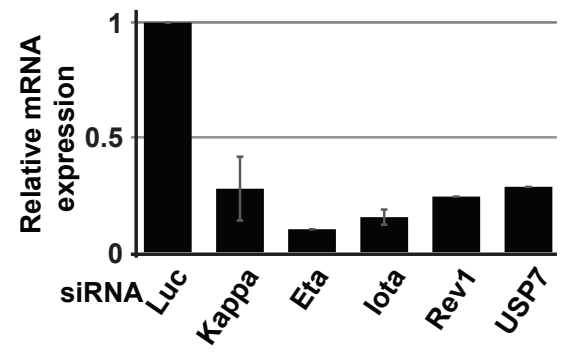

\section{C}

293T
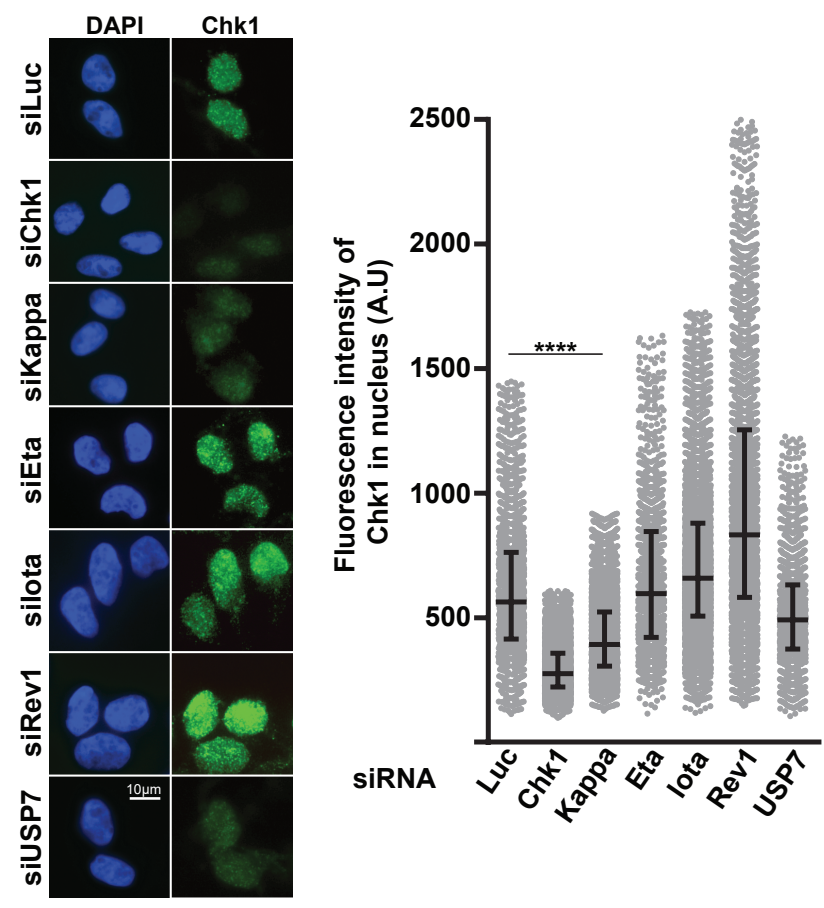


\section{Supplemental figure 3}

A HCT116

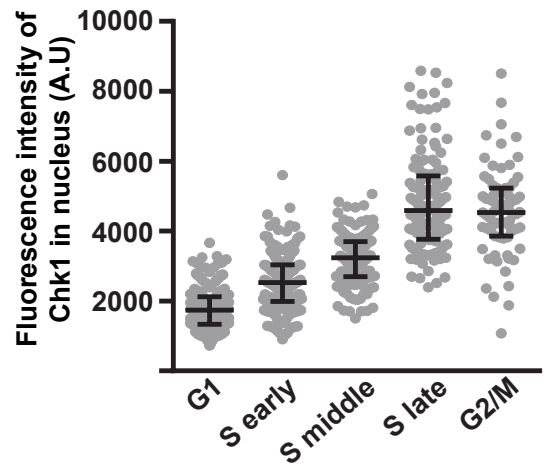

B

HCT116

RKO
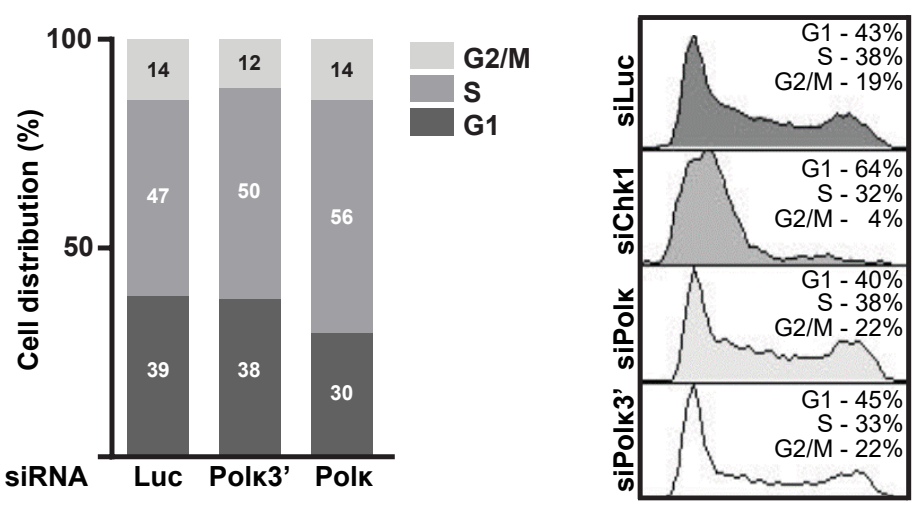


\section{Supplemental figure 4}

A

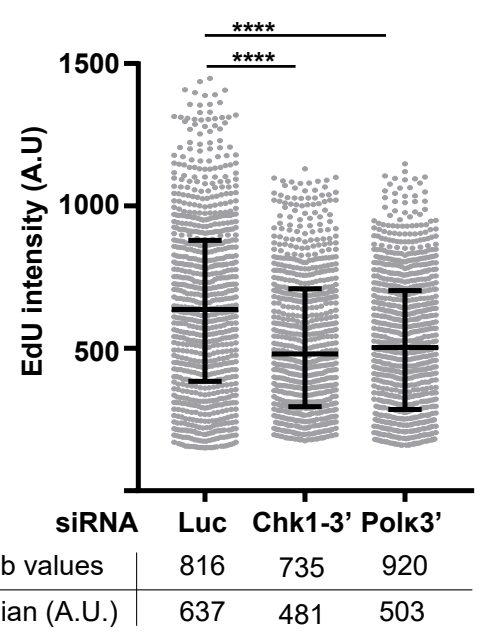

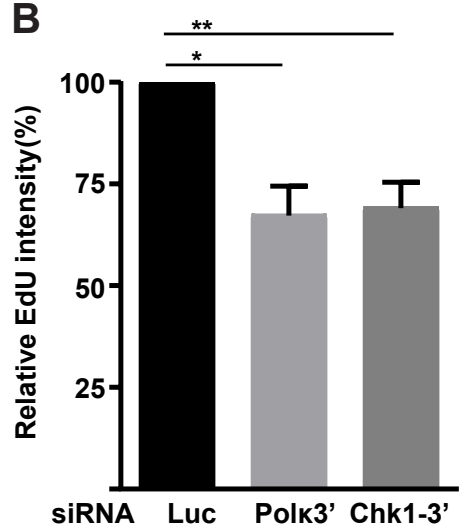




\section{Supplementary materiel and methods}

Cells were lysed in a buffer containing $50 \mathrm{mM}$ Tris $\mathrm{pH} 7.5,300 \mathrm{mM} \mathrm{NaCl}, 1 \%$ Triton, $5 \mathrm{mM}$ EDTA, $1 \mathrm{mM}$ DTT, supplemented with inhibitors. Cell lysates were cleared by centrifugation for $10 \mathrm{~min}$ at $10000 \mathrm{rpm}$. Cell extracts were boiled in loading buffer (Biorad $4 \mathrm{X}$ laemmli sample buffer) added with DTT 0.1M.

\section{Supplemental figure 1: Chk1 protein level is reduced in the nucleus of mammalian cells depleted for Pol $\kappa$}

(A) Western Blot analysis of nuclear extracts from MRC5-SV cells transfected with a control siRNA (Luc), siRNA targeting the coding sequence of Pol $\kappa$ (Polk) or Chk1 (Chk1). Immunodetected proteins are indicated in the figure. Fibrillarin and ORC2 are shown as loading controls. (B) Relative Chk1 or Pol Kappa protein levels in siPol $\kappa$ whole cell extracts of MRC5SV cells were normalized to siLuc condition (quantity of Chk1, quantity of Pol Kappa respectively). Data from 9 independent experiments are plotted. The regression curve (dashed line) and R-square are shown. Western Blot analysis of Pol $\kappa$ and GFP- Pol $\kappa$ in nuclear extracts of MRC5-SV (C) and HCT116 cells (D), 48h after co-transfection with a control siRNA (Luc) or targeting the 3'UTR of Pol $\kappa$ (Polk3') with a vector expressing either GFP-empty or GFP-Pol $\kappa$ (GFP-Polk). MCM7 is shown as a loading control. (E) Western blot analysis of Chk1 and Pol $\kappa$ in RKO, HCT116 and 293T nuclear extracts $48 \mathrm{~h}$ after transfection with a control siRNA (Luc) or Pol $\kappa$ si RNA (Polk). Cells were untreated or treated with $1 \mathrm{mM} \mathrm{HU}$ for $1 \mathrm{~h}$. Fibrillarin or actinin are shown as protein-loading controls. Quantification of Chk1 is relative to siLuc condition.

\section{Supplemental figure 2: Among the Y-DNA polymerase family, only the Pol $\kappa$ depletion causes a Chk1 nuclear drop} Efficiency of mRNA silencing was measured by RT-qPCR in HCT116 (A) and RKO (B) cells. The mRNA quantified is the one targeted by the siRNA indicated on the figure. Relative expressions were normalized to siluc condition. (C) Representative images and quantification of Chk1 immunostaining (green) in 293T cells transfected with the indicated siRNAs and DNA was stained with DAPI. The fluorescence intensity of Chk1 was quantified in each nucleus. Medians with $25 \%$ and $75 \%$ interquartile ranges were represented $\left({ }^{* * *} p<0.0001\right.$; Mann-Whitney test). Scale bar, $10 \mu \mathrm{m}$. A.U = arbitrary units.

\section{Supplemental figure 3: The Pol א-dependent Chk1 downregulation is not due to cycle arrest in G1}

HCT116 or RKO cells were transfected with control siRNA (Luc), siRNA targeting the 3'UTR of Pol $\kappa$ (Polk3'), the coding sequence of Pol $\kappa$ (Polk) or Chk1 (Chk1). 48h after transfection, asynchronous cells were pulse-labelled with EdU for 30 min $(10 \mu \mathrm{M})$ and processed as in figure 3. (A) Quantification of Chk1 immunostaining all along the cell cycle in HCT116 cells transfected control siRNA. A.U = arbitrary units. (B) No G1 accumulation in Pol $\kappa$ depleted cells. Cell cycle distribution from QIBC analysis in HCT116 cells (left) or from FACS analysis in RKO cells (right) after transfection with indicated siRNAs. Percentage of cells in each phase is indicated in the bar graphs or the FACS profiles.

\section{Supplemental figure 4: Pol $\kappa$ is required to maintain the global replication rate}

(A) Cells were transfected with control siRNA (Luc), siRNA targeting the 3'UTR of Chk1 (Chk1-3') or Pol $\kappa$ (Polk3'). 48h after transfection, asynchronous cells were pulse-labelled with EdU for 30 min $(10 \mu \mathrm{M})$. Nuclear EdU intensities were quantified in S phase nuclei. Medians with $25 \%$ and $75 \%$ interquartile ranges are represented. $(* * * * p<0.0001 ;$ MannWhitney test) $A . U=$ arbitrary units. (B) EdU intensity relative to control conditions is determined in 3 independent experiments and the mean ( \pm SEM) of medians relative to siLuc condition is presented. ( ${ }^{*} p<0.05 ;{ }^{* *} p<0.01 ; \mathrm{t}$-test). 